\title{
The resilience scale: factorial structure, reliability, validity, and parenting-related factors among disaster-exposed adolescents
}

\author{
Xuliang Shi ${ }^{1^{*}}$, Shuo Wang ${ }^{1}$, Zhen Wang ${ }^{2}$ and Fang Fan ${ }^{3^{*}}$
}

\begin{abstract}
Background: In this study, we examined psychometric properties of the Chinese version of the Resilience Scale (RS) and parenting-related factors associated with resilience among disaster-exposed adolescents.

Methods: Eighteen months after the earthquake, a total of 1266 adolescents $(43.4 \%$ male, mean age $=15.98 ; \mathrm{SD}=$ 1.28) were assessed using the RS, the Post-traumatic Stress Disorder Self-Rating Scale, the Depression Self-rating Scale for Children, the Screen for Child Anxiety Related Emotional Disorders, and Parental Bonding Instrument.

Results: Through exploratory factor analyses (EFAs) and parallel analysis, responses were characterized into a 3factor structure: personal competence, meaningfulness, and acceptance of self and life. Cronbach's alpha coefficient for the RS was 0.89 and the test-retest reliability coefficient was 0.72 . In terms of predictive validity, resilience was found to be a significant predictor for PTSD, depression, and anxiety. Multiple regression analysis showed that maternal parenting styles were significant predictors of resilience after adjusting for gender, age, sibling number, and earthquake experiences.
\end{abstract}

Conclusions: The Chinese version of RS is a reliable and valid tool for assessing resilience among adolescent survivors after disasters. The implications for research and resilience-oriented interventions were also discussed.

Keywords: Psychometric properties, Factors, Resilience scale, Adolescents, Earthquake

\section{Background}

Adverse experiences (e.g., natural disasters, war, terrorism, and sexual/physical abuse) during childhood or adolescence can result in long-term impairment of one's psychosocial functioning [1-4]. Although most people encounter various adverse or traumatic events in the course of their lives, their reactions to such events are not universal [5]. Some people may exhibit psychological

\footnotetext{
*Correspondence: shixl163@163.com; fangfan@scnu.edu.cn

'School of Education, Hebei University, Baoding 071002, Hebei, China

${ }^{3}$ School of Psychology, Center for Studies of Psychological Application, and Key Laboratory of Mental Health and Cognitive Science of Guangdong Province, South China Normal University, Guangzhou 510631, China Full list of author information is available at the end of the article
}

difficulties, while others actively respond to disasters, and may even attain post-traumatic growth. Resilience is defined as the ability to bounce back from social disadvantages or highly adverse conditions. Elucidating the role of resilience in children and adolescents in the aftermath of traumatic events can help improve their wellbeing and suppress the risk of developing psychopathologies, including posttraumatic stress disorder (PTSD), depression, and anxiety [6-8].

Despite the fact that there is no universally accepted definition of resilience, two core concepts have been previously mentioned: adversity and positive adaptation. Bonanno defined resilience as the ability to maintain a

(c) The Author(s). 2021 Open Access This article is licensed under a Creative Commons Attribution 4.0 International License, which permits use, sharing, adaptation, distribution and reproduction in any medium or format, as long as you give appropriate credit to the original author(s) and the source, provide a link to the Creative Commons licence, and indicate if changes were made. The images or other third party material in this article are included in the article's Creative Commons licence, unless indicated otherwise in a credit line to the material. If material is not included in the article's Creative Commons licence and your intended use is not permitted by statutory regulation or exceeds the permitted use, you will need to obtain permission directly from the copyright holder. To view a copy of this licence, visit http://creativecommons.org/licenses/by/4.0/. The Creative Commons Public Domain Dedication waiver (http://creativecommons.org/publicdomain/zero/1.0/) applies to the data made available in this article, unless otherwise stated in a credit line to the data. 
relatively stable psychological and physical functioning during adversity [5]. Based on increasing interest in this concept, many scales have been developed to assess resilience in development psychology, including the Resilience Scale (RS) [9], Connor-Davidson Resilience Scale (CD-RISC) [10], Resilience Scale for Adults (RSA) [11], and Brief Resilience Coping Scale (BRCS) [12]. Among them, one scale widely used in prior studies is the Resilience Scale [13].

The Resilience Scale (RS) was initially developed from a qualitative study [9]. In this study, 24 elderly women who had demonstrated a successful adaptation to traumatic events were interviewed. Five components (equanimity, perseverance, meaningfulness, self-reliance, and existential aloneness) were found to be correlated with resilience. In an empirical study [9], two factors (personal competence and acceptance of self and life) were extracted from 25 RS items through exploratory factor analysis. Personal competence consists of 17 items including self-reliance, perseverance, mastery, and resourcefulness, while acceptance of self and life includes 8 items involving acceptance of life and a sense of peace in spite of adversities. The 25-item RS has been translated into many languages, including Chinese, Dutch, Swedish, and Japanese, all of which have shown good psychometric characteristics [7, 14-16]. Studies have documented that the mental structure of resilience may vary depending on cultural contexts. For example, 5 factors were identified in the Swedish version [15], whereas 3 factors were extracted from the Brazilian version [17]. Furthermore, inconsistent results from different samples of the same country have been documented. For instance, after the 2010 Haitian earthquake, a 5-factor model was found to be supported by child and adolescent survivors [18], whereas a 3-factor model was confirmed by adult survivors [19]. Therefore, it is important to examine the psychometric properties of the 25-item RS under different socio-cultural backgrounds.

Risk and protective factors associated with resilience are of particular importance. According to the current resilience models, the factors affecting resilience can be grouped into internal and external factors. Internal factors, such as demographic (gender and age) and psychological (optimism and gratitude) factors, are generated from within an individual. External factors, such as family functions and school climate, are generated from outside of a person. Among the external factors, parenting styles are of particular importance. Parenting styles can affect an adolescent's mental health [20, 21]. Positive parenting styles, such as warm, supportive, and acceptance, have been associated with increasing resilience, for example, in protecting adolescents from depression and anxiety. In a study involving elementary school children, it was found that an authoritative parenting style was negatively associated with parent- and teacher-rated maladaptive behavior, and positively correlated with indicators of healthy adjustment [22]. In the Chinese culture, mothers spend more time taking care of their children compared to fathers, and children tend to feel closer to their mothers than their fathers. Mothers are more involved in educating their children, and thus, maternal parenting styles may exert a greater impact on children's adjustment. The above studies are limited by the fact that they mainly involved normal children and adolescents. These associations have not been elucidated in traumatized adolescents. Based on this limitation, we systematically examined the contribution of maternal parenting styles to resilience among adolescent survivors after a natural disaster, which may inform the development of interventions aimed at improving resilience.

At 14:28 on the 12th of May, 2008, a destructive earthquake occurred in Sichuan province of southwest China. It resulted in 69,227 deaths, 374,176 injuries and 18,222 missing people. A great number of the children and adolescents suffered the direct effects of the earthquake. Six months after the earthquake, a cohort study was conducted in Dujiangyan city, one of the most severely damaged areas [23]. With the data on resilience and parenting styles among adolescent survivors from this cohort, the objectives of the current study were: i. To examine the underlying structure and the psychometric properties of the 25-item RS in the Chinese context; and ii. To assess the resilience levels and determine whether maternal parenting styles are important predictors of resilience among adolescent survivors.

\section{Materials and methods \\ Participants and study design}

This study was part of the Wenchuan Earthquake Adolescent Health Cohort (WEAHC). In WEAHC, participants were surveyed for a total of five times at an interval of 6 months. All surveys were conducted between December, 2008 and January, 2011. Sampling and data collection methods were as previously described [23]. Briefly, a total of 1573 adolescents affected by the Wenchuan earthquake were surveyed at baseline (about 6 months after the earthquake). In this study, data from the third survey conducted in December 2009 (about 18 months after the earthquake) was used. A total of 1266 students were followed up at this stage. Among the students who participated, $43.4 \%$ were males, with a mean age of $15.98 \pm 1.28$ years. Most of the students (83.3\%) were the only child in their families. With respect to earthquake exposure, $25.0 \%$ reported dead, missing, or injured family members; $58.8 \%$ witnessed traumatic scenes; $42.6 \%$ reported severe house damage; while $21.3 \%$ suffered the loss of family property. 
Self-administered questionnaires were administered to target students in classroom settings. The students were informed that they were free to withdraw from the study at any time. The questionnaires were filled at an average of $30 \mathrm{~min}$ per student. The study methods were performed in accordance with the relevant guidelines and regulations. Ethical approval for this study was obtained from the Human Research Ethics Committee of South China Normal University, with permission and support from the participating school boards and the Chengdu Women's Federation. A written informed consent was also obtained from the participating students and their parents, or guardians.

\section{Measures}

\section{Demographic characteristics}

The collected demographic information included gender $(0=$ male, $1=$ female $)$, age, and sibling number $(0=$ more than one child, 1 = only one child).

\section{Earthquake experiences}

Four items were used to evaluate the participants' earthquake experiences at baseline: i. Dead, missing, and/or injured family members; ii. House damage; iii. Property loss (other than house damage); and iv. Direct witness of the tragic disaster. The first three items were scored on a 5-point scale ranging from 1 (the highest level of exposure) to 5 (the lowest level of exposure). The last item was scored as: $1=$ not directly seeing the disaster scene and 2 =directly seeing the disaster scene. Item scores were added to create a composite score for earthquake exposure, with higher scores (ranging from 4 to 17) indicating higher exposure levels.

\section{Resilience}

The Chinese version of Resilience Scale was used to assess resilience levels $[9,24]$. With permission from the original authors, the scale was translated into Chinese and then, back-translated by one English teacher and two graduate students majoring in psychology [24], until a consensus was reached. This scale includes 25 items and participants were asked to respond based on a 7point Likert scale ranging from strongly disagree (scored 1 ) to strongly agree (scored 7), with a higher score representing a higher resilience level. The Chinese version of RS has been shown to have adequate psychometric properties for Chinese adolescents [24]. The internal consistency of this RS version was 0.89 , while the testretest reliability after two weeks was 0.74 . In this study, Cronbach's alpha was 0.93 .

\section{Posttraumatic stress disorder symptoms}

The Post-traumatic Stress Disorder Self-Rating Scale (PTSD-SS) was used to evaluate PTSD symptoms [25].
The PTSD-SS was developed in accordance with the diagnostic criteria of PTSD as described in DSM-IV and the Chinese Classification of Mental Disorders. This scale entails 24 items, each rated on a 5 -point scale varying from 1 ("not at all") to 5 ("extremely severe"). The item scores were added to generate a total score ranging from 24 to 120 . The PTSD-SS exhibits satisfactory psychometric properties for Chinese adolescents [25]. In the current study, Cronbach's alpha was 0.95.

\section{Depression symptoms}

Depression symptoms were measured using the Depression Self-rating Scale for Children (DSRSC), which has good reliability and validity for use in Chinese children and adolescents $[26,27]$. This scale consists of 18 items, each rated on a 3 -point scale $(0=$ never, $1=$ sometimes, 2 = mostly). A higher total score (ranging from 0 to 36 ) indicates a higher level of depression. In the current study, Cronbach's alpha was 0.82 .

\section{Anxiety symptoms}

The Chinese version of the Screen for Child Anxiety Related Emotional Disorders (SCARED) is a 41-item selfreport measure designed to screen for anxiety disorders among children and adolescents [28, 29]. The items were rated on a 3 -point scale $(0=$ almost never, $1=$ sometimes, $2=$ often). A total score ranging from 0 to 82 was used in this study. In the current study, Cronbach's alpha was 0.94 .

\section{Maternal parenting styles}

Parental Bonding Instrument (PBI) was used to assess adolescents' perception of parenting styles. In this sample, most of the children's fathers were absent due to work related factors. Thus, we only examined the influence of maternal parenting styles on resilience. This scale includes three subscales: i. Care (e.g. Spoke to me in a warm and friendly voice); ii. Autonomy (e.g. Let me do those things I liked doing)", and ii. Overprotect (e.g. Tried to control everything I did)" [30, 31]. The first two subscales reflect positive parenting styles, while the last one reflects negative parenting styles. Care refers to the mother's affection and emotional warmth, empathy, and closeness. Autonomy reflects that mothers encourage their children to be independent. Overprotection reflects mother's excessive interference and control in children's behavior. This scale consists of 23 items (care: 11 items; autonomy: 6 items; overprotect: 6 items) rated on a 4point scale from 0 ("very unlike") to 3 ("very like"). The total score of the three subscales was used in the subsequent analysis. In the current study, Cronbach's alpha was 0.69 . 


\section{Analysis design}

Descriptive statistics were used to describe the total scores of resilience, while $t$-tests were separately performed to test the differences in gender and siblings on the total resilience score. To facilitate exploratory and confirmatory factor analysis (EFA \& CFA), the participants were assigned into two subsamples using a splitsampling random procedure in SPSS. Subsample $1(N=$ 628) was used for EFA while subsample $2(N=638)$ was used for CFA. In EFA analysis, principal component analysis (PCA) with oblique rotation was performed to obtain factor solution. Scree plot and parallel analysis Monte Carlo PCA for parallel analysis [32]; was used to determine the number of factors to be extracted. Items with factor loading greater than 0.40 were retained. In CFA analysis, these indices were used to assess the goodness of model fit: the comparative fit index (CFI), the Tucker-Lewis index (TLI), the root mean square error of approximation (RMSEA), and the standardized root mean residual (SRMR). Cronbach's $\alpha$ coefficients were used to determine internal consistency, and the test-retest reliability was evaluated using data from 200 participants, 6 months later. To assess the predictive validity of RS, a series of regression analyses were performed with the three mental disorders (PTSD, depression, and anxiety) as dependent variables. Third, multiple regression was performed to determine whether maternal parenting styles are important resilience predictors. All statistical analyses were performed using SPSS 23.0 and Mplus 7.4. All reported $p$ values were two-sided, and $p \leq 0.05$ was considered to be statistically significant.

\section{Results}

\section{Descriptive statistics}

The average resilience score was $110.89 \pm 26.25$. The $t$ test for independent samples revealed that male adolescents reported higher levels of resilience than females $(t=3.18, p<0.01$, Cohen's $d=0.18)$. Participants who had no siblings exhibited greater resilience than those with siblings $(t=2.36, p<0.05$, Cohen's $d=0.19)$. In addition, the item-total correlation coefficient of the 25 items were all above 0.40 , and ranged from 0.42 to 0.69 (see Table 1).

\section{Exploratory and confirmation factor analysis of the Chinese version of RS}

Exploratory factor analysis was performed to explore the factor structure for RS. The Kaiser-Meyer-Olkin (KMO) value was 0.83 while the Bartelett sphericity test was significant $\left(\chi^{2}=3671.39, d f=300, p<0.001\right)$, suggesting that the data was suitable for EFA. Five factors had an eigenvalue higher than 1 . However, the scree plot and parallel analysis allowed us to retain a three-factor model (Fig. 1), which accounted for $42.72 \%$ of the total variance. The factor loadings are shown in Table 1.

Factor 1 was labeled "personal competence", composed of 14 items reflecting self-reliance, mastery, and perseverance when people are faced with trauma. Factor 2 was labeled "meaningfulness", consisting of 6 items reflecting an individual's sense for having something for which to live. Factor 3 with 5 items was labeled "acceptance of self and life", suggesting flexibility, adaptability and a sense of peace in spite of adversity.

CFA for the 3-factor models in Sample 2 was performed to confirm the factor structure of the RS among Chinese adolescent survivors. The model was significant, $\chi^{2}(272)=1090.75, p<0.001$, which could be attributed to the large sample size. In addition, RMSEA $=0.04$, $\mathrm{CFI}=0.95$, TLI $=0.96$, and $\mathrm{SRMR}=0.04$, suggested an acceptable fit model. Moreover, we examined the twofactor model derived from Wagnild and Young [9] and the five-factor model with an eigenvalue higher than 1 . EFA analyses revealed a poor fit for these two models (fit indices of two-factor model: $\chi^{2} \quad(274)=1524.68$, $p<0.001, \mathrm{CFI}=0.85, \mathrm{GFI}=0.87$, and $\mathrm{RMSEA}=0.08$; fit indices of five-factor model: $\chi^{2} \quad(265)=1275.48$, $p<0.001, \mathrm{CFI}=0.81$, GFI $=0.74$, and $\mathrm{RMSEA}=0.15$ ).

\section{Internal consistency and test-retest reliability of the Chinese version of RS}

The internal consistency of the total RS was 0.89 , while Cronbach's alpha coefficients of the 3 factors were 0.89 , 0.83 , and 0.79 , respectively. These findings imply a relatively good internal consistency. The correlations among the three factors were significant at 0.01 , ranging from 0.44 to 0.64 . For the test-retest reliability, a total of 200 adolescents from the third survey were reevaluated in June, 2010 (about 24 months after the earthquake). The test-retest reliability coefficient (6-month interval) was found to be 0.72 for the whole scale, and 0.70, 0.75 and 0.68 for the 3 factors, respectively.

\section{Predictive validity}

To assess the predictive validity of RS, a series of regression equations were run. In the regression analysis, mental disorders (including PTSD, depression, and anxiety) were taken as dependent variables and resilience as independent variable. As shown in Table 2, after adjusting for gender, age, sibling number, and earthquake experiences, resilience significantly predicted PTSD $(\beta=-0.16$, $p<0.001)$, depression $(\beta=-0.35, p<0.001)$, and anxiety symptom $(\beta=-0.25, p<0.001)$.

\section{Maternal parenting styles as predictors of resilience}

As shown in Table 3, after adjusting for gender, age, sibling number, and earthquake experiences, participants who reported perceiving more maternal care $\beta=0.22$, 
Table 1 Resilience Scale: item means, standard deviations, item-total correlation and factor loadings

\begin{tabular}{|c|c|c|c|c|c|c|}
\hline Items $^{\text {a }}$ & $M$ & $S D$ & $\begin{array}{l}\text { Item-total correlation } \\
\text { b }\end{array}$ & $\begin{array}{l}\text { Factor } \\
1^{c}\end{array}$ & $\begin{array}{l}\text { Factor } \\
2\end{array}$ & $\begin{array}{l}\text { Factor } \\
3\end{array}$ \\
\hline I am determined. (10) & 4.08 & 1.79 & 0.57 & 0.63 & & \\
\hline I seldom wonder what the point of it all is. (11) & 4.74 & 1.62 & 0.63 & 0.63 & & \\
\hline $\begin{array}{l}\text { I can get through difficult times because I have experienced difficulty before. } \\
\text { (13) }\end{array}$ & 4.80 & 1.67 & 0.65 & 0.60 & & \\
\hline I can be on my own if I have to. (5) & 5.56 & 1.57 & 0.51 & 0.60 & & \\
\hline I usually take things in stride. (7) & 4.62 & 1.67 & 0.69 & 0.59 & & \\
\hline I take things one day at a time. (12) & 4.13 & 1.69 & 0.63 & 0.58 & & \\
\hline I feel that I can handle many things at a time. (9) & 4.04 & 1.68 & 0.57 & 0.56 & & \\
\hline I am able to depend on myself more than anyone else. (3) & 4.60 & 1.70 & 0.43 & 0.53 & & \\
\hline I have self-discipline. (14) & 4.57 & 1.78 & 0.57 & 0.47 & & \\
\hline I feel proud that I have accomplished things in life. (6) & 5.50 & 1.55 & 0.56 & 0.45 & & \\
\hline When I'm in a difficult situation, I can usually find my way out of it. (23) & 4.51 & 1.54 & 0.65 & 0.44 & & \\
\hline When I make plans, I follow through with them. (1) & 3.74 & 1.63 & 0.50 & 0.43 & & \\
\hline I usually manage one way or another. (2) & 4.69 & 1.65 & 0.55 & 0.42 & & \\
\hline I have enough energy to do what I have to do. (24) & 4.74 & 1.70 & 0.65 & 0.42 & & \\
\hline I keep interested in things. (15) & 4.73 & 1.78 & 0.57 & & 0.80 & \\
\hline I can usually find something to laugh about. (16) & 5.21 & 1.75 & 0.56 & & 0.72 & \\
\hline Keeping interested in things is important to me. (4) & 4.73 & 1.89 & 0.53 & & 0.69 & \\
\hline My life has meaning. (21) & 5.01 & 1.76 & 0.57 & & 0.58 & \\
\hline I am friends with myself. (8) & 4.96 & 1.82 & 0.58 & & 0.53 & \\
\hline My belief in myself gets me through hard times. (17) & 4.79 & 1.70 & 0.61 & & 0.52 & \\
\hline Sometimes I make myself do things whether I want to or not. (20) & 3.98 & 1.83 & 0.42 & & & 0.61 \\
\hline I do not dwell on things that I can't do anything about. (22) & 4.35 & 1.99 & 0.43 & & & 0.52 \\
\hline It's okay if there are people who don't like me. (25) & 4.48 & 2.07 & 0.42 & & & 0.51 \\
\hline I can usually look at a situation in a number of ways. (19) & 4.52 & 1.61 & 0.59 & & & 0.50 \\
\hline In an emergency, I'm someone people can generally rely on. (18) & 4.23 & 1.67 & 0.51 & & & 0.43 \\
\hline Eigenvalue & & & & 7.83 & 1.48 & 1.37 \\
\hline Variance explained (\%) & & & & 31.30 & 5.93 & 5.49 \\
\hline
\end{tabular}

Note: ${ }^{a}$ All items of Resilience Scale were presented. ${ }^{b}$ All item coefficients were significant at the alpha 0.01 level. ${ }^{c}$ Coefficients below 0.40 are not displayed in the table

$p<0.001)$, more mothers' autonomy-relevant parenting $(\beta=0.22, p<0.001)$, and less maternal overprotect $(\beta=$ $-0.16, p<0.001)$ had higher levels of resilience.

\section{Discussion}

The first objective of this study was to evaluate the psychometric properties of the Chinese version of the RS in 1266 adolescent survivors of the Wenchuan earthquake. Factor analysis showed that a 3-factor model (factor 1: personal competence; factor 2: meaningfulness; factor 3: acceptance of self and life) was acceptable. Personal competence refers to the willingness or belief that individuals should rely on their own strengths to reconstruct their lives when they encounter setbacks. Meaningfulness refers to the realization that life has a purpose and the sense of having something for which to live.
Acceptance of self and life means that individuals can always appreciate life and a sense of peace in the face of adversity. Compared to the study by Wagnild and Young [9], there is a similarity between their factors and our two factors (factor 1 and factor 3). These two factors were also validated using a sample of adult survivors following Haiti's earthquake [19]. In addition, the second factor (meaningfulness) in our study was also presented within the five characteristics of resilience as defined by the original authors [9]. This factor measured the extent by which the belief in having a goal in life is established. It is the recognition that there is something for which to live.

The reliability coefficient of the RS in our study was 0.89 , which was comparable to other reliability studies $[7,14]$. As noted in a previous review, Wagnild [33] also 


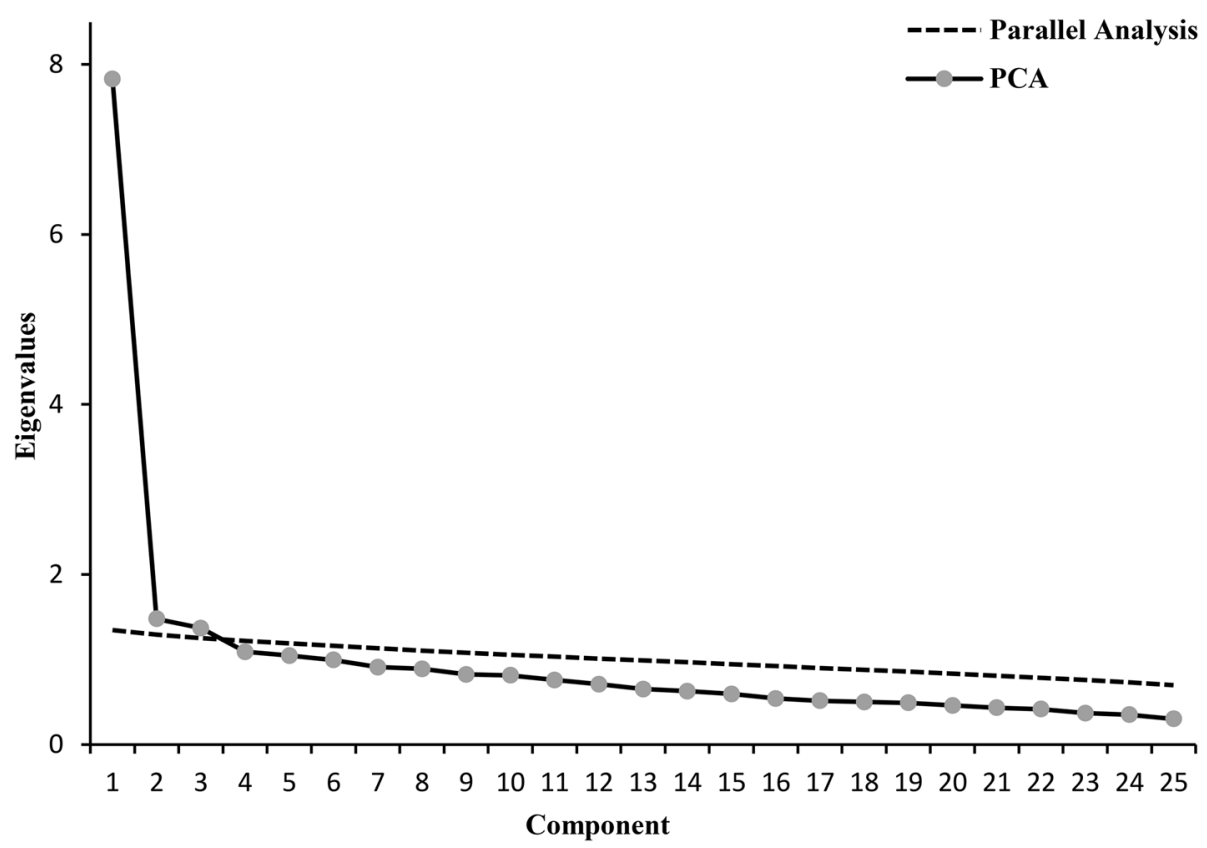

Fig. 1 Scree plot and parallel analysis of eigenvalues based on principal component analysis of the Resilience Scale

found that the internal consistency of the RS was consistently high in 11 of 12 reviewed studies (Cronbach's alpha coefficient ranged from 0.85 to 0.94 ). In addition, the test-retest coefficient of our study was 0.72 , which was lower than the results of previous studies. For example, the test-retest correlation (1-month interval) was 0.78 in the study by Nygren, et al. [34], and 0.82 (6month interval) in the study by Lei, et al. [7] . Since a limited number of studies have evaluated the test-retest reliability of the RS, more studies should be performed to test the stability of RS. Regarding the predictive validity of RS, we found that resilience predicted PTSD, depression, and anxiety after adjusting for some confounders. Compared to individuals with low resilience, individuals with a high resilience exhibited fewer PTSD, depression, and anxiety symptoms. These results are consistent with those of previous studies [35, 36]. For example, three months after the Jiuzhaigou earthquake, a total of 607 participants were recruited from the heavy damaged areas and assessed. It was found that resilience was significantly correlated to the severity of

Table 2 Regression analysis evaluating the predictive validity of RS on mental disorders

\begin{tabular}{llllll}
\hline Outcome variables $^{\mathrm{a}}$ & $\boldsymbol{B}$ & S.E. & $\boldsymbol{\beta}$ & $\boldsymbol{t}$ & $\boldsymbol{p}$ \\
\hline PTSD & -0.09 & 0.02 & -0.16 & -5.77 & $<0.001$ \\
Depression & -0.09 & 0.01 & -0.35 & -13.47 & $<0.001$ \\
Anxiety & -0.15 & 0.02 & -0.25 & -9.40 & $<0.001$
\end{tabular}

Note: RS = Resilience Scale. ${ }^{\text {a }}$ Adjusted for gender, age, sibling number and earthquake experiences
PTSD, depression, and anxiety symptoms [37]. These correlations were attributed to several factors. First, highly resilient adolescents often adopt effective cognitive emotion regulation strategies [38] that serve to attenuate the impact of mental illness. Second, resilient adolescents have positive emotions [39] and optimistic attitudes [40], all of which would contribute to reducing the impact of mental illness.

After the earthquake, male adolescents showed higher levels of resilience than females, inconsistent with previous studies that did not find gender-related differences $[18,33]$. However, our finding was in agreement with that of Lei, et al. [7] who reported that male college students had higher resilience scores than females. Moreover, previous studies that used the Connor-Davidson Resilience Scale also found that male participants had significantly higher resilience scores than females [41, 42]. This could be attributed to the fact that, compared to males, females have abnormal HPA responses to stress, which may makes them more sensitive to stress [43]. The participants who had no siblings reported greater resilience than those with siblings. Inferably,

Table 3 Multiple regression analysis predicting resilience

\begin{tabular}{llllll}
\hline Predictors $^{\text {a }}$ & B & S.E. & $\boldsymbol{\beta}$ & $\boldsymbol{t}$ & $\boldsymbol{p}$ \\
\hline Mother-care & 1.61 & 0.23 & 0.22 & 7.13 & $<0.001$ \\
Mother-autonomy & 1.39 & 0.19 & 0.22 & 7.35 & $<0.001$ \\
Mother-overprotect & -1.25 & 0.24 & -0.16 & -5.15 & $<0.001$ \\
\hline
\end{tabular}

Note: ${ }^{a}$ adjusting for gender, age, sibling number, and earthquake experiences 
compared to children with siblings, the only child might receive extensive attention and support from family members or other closed ones.

The second objective of this study was to determine whether maternal parenting styles had unique contributions to resilience. Teenagers whose mothers preferred caring and autonomy-relevant parenting had higher levels of resilience. This kind of mother considers the children's wish and opinions when appropriate, gives them a positive feedback and corrects their negative behaviors. These results are consistent with those of previous studies [44, 45]. For example, one South African study involving a sample of 360 teenagers found that authoritative parenting, characterized by warmth and democracy, was one of the most important predictors of resilience [44]. Similar results were also reported in elderly adults [45]. Moreover, overprotected teenagers were found to have a lower resilience. This result was consistent with previous studies [46, 47]. For instance, in a sample of 200 college students and their parents, the researchers found that perceptions of maternal control were a powerful predictor for students' anxiety [48]. Overprotective mothers always try to protect their children against experiencing life or enduring struggles that make them anxious, which might hamper their independence and self-confidence, thus reducing their selfefficacy and resilience.

Several limitations should be noted when interpreting the findings. First, the measurements of resilience in this study were self-reported by adolescents, which may be biased by social desirability. Multiple assessments (e.g. parents' reports or teachers' reports) should be considered in future studies. Second, participants in this study were only recruited from among adolescents who had suffered a devastating earthquake, which limits generalization of the conclusions to adult populations and other types of acute or chronic traumatic events. It is also possible that the sampling range may bias the validity of the factors. These findings should be verified using larger and representative samples. Third, resilience is a multidimensional concept that may be affected by a variety of factors, such as biological, psychosocial, or contextual. Future studies should use multiple markers that can increase or decrease resilience.

Notwithstanding these limitations, this study shows that the RS is a reliable and valid tool for assessing resilience among adolescent survivors after disasters. Resilience scores may be useful for identifying vulnerable individuals at a high risk of developing mental disorders following natural disasters, so that they might be referred for mental health services. The scale can be administered to a large number of individuals at a low cost, and can maximize the utilization of limited resources in the occurrence of natural disasters. Large scale screening methods may not only be more costeffective, but can also reduce stigma and discrimination, which might be induced by using scales of psychiatric symptoms as criteria for referral to services. This study also contributes to the identification of factors associated with resilience, which may provide some insights for the development of resilience-oriented interventions. Interventions aimed at enhancing resilience can be carried out in school settings. These interventions have been shown to be effective in reducing the symptoms of depression and anxiety [49]. Therefore, from a public health perspective, resilience-oriented prevention and early intervention programs are a relatively low-cost investment with the potential for excellent returns.

\section{Conclusions}

The Chinese version of the Resilience Scale (RS) has good psychometric properties, and the 3-factor model (factor 1: personal competence; factor 2: meaningfulness; factor 3: acceptance of self and life) fits best. In addition, multiple regression analysis showed that maternal parenting styles are significant predictors for adolescent survivors' resilience.

\section{Acknowledgements \\ The authors want to express their sincere gratitude to all the teachers and students who participated in this survey.}

\section{Authors' contributions}

Xuliang Shi contributed to the first drafting of the paper. Shuo Wang and Zhen Wang contributed to the critical revision of the paper. Fang Fan contributed to the conception of the study. All authors approved the final manuscript for publication.

\section{Funding}

The study was funded by the National Natural Science Foundation of China (Grant No. 31900789, 31271096), and the Advanced Talents Incubation Program of the Hebei University (Grant No. 521000981309).

\section{Availability of data and materials}

The datasets used and/or analyzed during the current study are available from the corresponding author on reasonable request.

\section{Declarations}

Ethics approval and consent to participate

The study methods were performed in accordance with the relevant guidelines and regulations. Ethical approval for this study was obtained from the Human Research Ethics Committee of South China Normal University, with permission and support from the participating school boards and the Chengdu Women's Federation. A written informed consent was also obtained from the participating students and their parents, or guardians.

\section{Consent for publication}

Not applicable.

\section{Competing interests}

No

\section{Author details}

'School of Education, Hebei University, Baoding 071002, Hebei, China.

${ }^{2}$ School of Public Administration, Xinhua College of Sun Yat-sen University, Dongguan 510520, Guangdong, China. ${ }^{3}$ School of Psychology, Center for Studies of Psychological Application, and Key Laboratory of Mental Health 
and Cognitive Science of Guangdong Province, South China Normal University, Guangzhou 510631, China.

\section{Received: 8 October 2020 Accepted: 5 March 2021 Published online: 10 March 2021}

\section{References}

1. Masten AS, Narayan AJ. Child development in the context of disaster, war, and terrorism: pathways of risk and resilience. Annu Rev Psychol. 2012;63(1): 227-57. https://doi.org/10.1146/annurev-psych-120710-100356.

2. Brown J, Cohen P, Johnson JG, Smailes EM. Childhood abuse and neglect: specificity of effects on adolescent and young adult depression and suicidality. J. Am. Acad. Child Adolesc. Psychiatr. 1999;38(12):1490-6.

3. Self-Brown, S.; Lai, B.; Patterson, A.; Glasheen, T., The impact of natural disasters on youth: $A$ focus on emerging research beyond internalizing disorders. Curr. Psychiatry Rep. 2017, 19, (8), 53, 1-7.

4. Trickey D, Siddaway AP, Meiser-Stedman R, Serpell L, Field AP. A metaanalysis of risk factors for post-traumatic stress disorder in children and adolescents. Clin. Psychol. Rev. 2012;32(2):122-38.

5. Bonanno GA. Loss, trauma, and human resilience: have we underestimated the human capacity to thrive after extremely aversive events? Am. Psychol. 2004;59(1):20-8.

6. Ying $L, W u X$, Lin $C$, Jiang $L$. Traumatic severity and trait resilience as predictors of posttraumatic stress disorder and depressive symptoms among adolescent survivors of the wenchuan earthquake. PloS one. 2014; 9(2):e89401.

7. Lei M, Li C, Xiao X, Qiu J, Dai Y, Zhang Q. Evaluation of the psychometric properties of the Chinese version of the resilience scale in Wenchuan earthquake survivors. Compr. Psychiat. 2012;53(5):616-22.

8. Green KT, Calhoun PS, Dennis MF, Beckham JC. Exploration of the resilience construct in posttraumatic stress disorder severity and functional correlates in military combat veterans who have served since September 11, 2001. J. Clin. Psychiatry. 2010;71(7):823-30. https://doi.org/10.4088/JCP.09m05780blu.

9. Wagnild GM, Young HM. Development and psychometric evaluation of the resilience scale. J Nurs Meas. 1993;1(2):165-78.

10. Connor KM, Davidson JR. Development of a new resilience scale: the Connor-Davidson resilience scale (CD-RISC). Depress. Anxiety. 2003;18(2):7682. https://doi.org/10.1002/da.10113.

11. Friborg $\mathrm{O}$, Hjemdal $\mathrm{O}$, Rosenvinge $\mathrm{JH}$, Martinussen $\mathrm{M}$. A new rating scale for adult resilience: what are the central protective resources behind healthy adjustment? Int. J. Methods Psychiatr. Res. 2003;12(2):65-76.

12. Sinclair VG, Wallston KA. The development and psychometric evaluation of the brief resilient coping scale. Assessment. 2004;11(1):94-101. https://doi. org/10.1177/1073191103258144.

13. Ahern NR, Kiehl EM, Sole ML, Byers J. A review of instruments measuring resilience. Issues. Compr. Pediatr. Nurs. 2006;29(2):103-25.

14. Nishi D, Uehara R, Kondo M, Matsuoka Y. Reliability and validity of the Japanese version of the resilience scale and its short version. BMC Res Notes. 2010;3(1):310. https://doi.org/10.1186/1756-0500-3-310.

15. Lundman B, Strandberg G, Eisemann M, Gustafson Y, Brulin C. Psychometric properties of the Swedish version of the resilience scale. Scand. J. Caring Sci. 2007;21(2):229-37. https://doi.org/10.1111/j.1471-6712.2007.00461.x.

16. Portzky M, Wagnild G, De Bacquer D, Audenaert K. Psychometric evaluation of the Dutch Resilience Scale RS-nl on 3265 healthy participants: a confirmation of the association between age and resilience found with the Swedish version. Scand. J. Caring Sci. 2010;24(Suppl 1):86-92.

17. Pesce RP, Assis SG, Avanci JQ, Santos NC, Malaquias JV, Carvalhaes R. Crosscultural adaptation, reliability and validity of the resilience scale. Cad Saude Publica. 2005:21(2):436-48. https://doi.org/10.1590/S0102-311X20050002 00010.

18. Cenat JM, Derivois D. Psychometric properties of the Creole Haitian version of the Resilience Scale amongst child and adolescent survivors of the 2010 Earethquake. Compr. Psychiatry. 2014;55(2):388-95.

19. Cenat JM, Derivois D, Hebert M, Eid P, Mouchenik Y. Psychometric properties of the Haitian creole version of the resilience scale with a sample of adult survivors of the 2010 earthquake. Compr Psychiatry. 2015;63:96104. https://doi.org/10.1016/j.comppsych.2015.09.002

20. Uji M, Sakamoto A, Adachi K, Kitamura T. The impact of authoritative, authoritarian, and permissive parenting styles on children's later mental health in Japan: focusing on parent and child gender. J Child Fam Stud. 2014;23(2):293-302.
21. Milevsky A, Schlechter M, Netter S, Keehn D. Maternal and paternal parenting styles in adolescents: associations with self-esteem, depression and life-satisfaction. J Child Fam Stud. 2007;16(1):39-47.

22. Kaufmann D, Gesten E, Santa Lucia RC, Salcedo O, Rendina-Gobioff G, Gadd R. The relationship between parenting style and children's adjustment: the parents' perspective. J Child Fam Stud. 2000;9(2):231-45. https://doi.org/10.1 023/A:1009475122883

23. Fan F, Zhou Y, Mo L, Zhang W, Xie J, Liu X, Group, W. S. Cohort profile: the Wenchuan earthquake adolescent health cohort study. Int J Epidemiol. 2016;46(1):27-8

24. Fan F. Psychopathology of anxiety and depression of left-behind children and empirical study of resilience. Changsha, PRC: Central South University; 2008.

25. Liu X, Ma D, Liu L, Zhao G, Li C, Yang J, Shun L. Development of the posttraumatic stress disorder self-rating scale and its reliability and validity. Chin J Behav Med Sci. 1998;7:93-6.

26. Birleson P. The validity of depressive disorder in childhood and the development of a self-rating scale: a research report. J Child Psychol Psyc. 1981;22(1):73-88. https://doi.org/10.1111/j.1469-7610.1981.tb00533.x.

27. Su L, Wang K, Zhu Y, Luo X, Yang Z. Norm of the depression self-rating scale for children in Chinese urban children. Chin Ment Health J. 2003:17(8): $547-9$.

28. Cao X, Wang L, Cao C, Zhang J, Elhai J. PTSD latent classes and class transitions predicted by distress and fear disorders in disaster-exposed adolescents. J Clin Child Adolesc. 2019;48(2):332-42. https://doi.org/10.1 080/15374416.2017.1410825

29. Su L, Wang K, Fan F, Su Y, Gao X. Reliability and validity of the screen for child anxiety related emotional disorders (SCARED) in Chinese children. J Anxiety Disord. 2008;22(4):612-21. https://doi.org/10.1016/j.janxdis.2007.05. 011.

30. Parker G, Tupling H, Brown L. Parental bonding instrument (PBI). Br. J Med Psychol. 1979:52(1):1-10. https://doi.org/10.1111/j.2044-8341.1979.tb02487.x.

31. Yang H, Chu Y, Liu L, Liu Q, Chen Z, Liu W, Zhong A. The revision of parental bonding instrument for Chinese college students. Chinese J Clin Psychol. 2009;17(4):434-6.

32. Watkins MW. Monte Carlo PCA for parallel analysis. State College, PA. 2000: 432-42.

33. Wagnild GM. A review of the resilience scale. J Nurs Meas. 2009:17(2):10513. https://doi.org/10.1891/1061-3749.17.2.105

34. Nygren B, Randstrom KB, Lejonklou AK, Lundman B. Reliability and validity of a Swedish language version of the resilience scale. J Nurs Meas. 2004; 12(3):169-78. https://doi.org/10.1891/jnum.12.3.169.

35. Green KT, Calhoun PS, Dennis MF, Beckham JC. Exploration of the resilience construct in posttraumatic stress disorder severity and functional correlates in military combat veterans who have served since September 11, 2001. J Clin Psychiatry. 2010;71(7):823-30. https://doi.org/10.4088/JCP.09m05780blu.

36. Miroševič Š, Klemenc-Ketiš Z, Selič P. The 14-item resilience scale as a potential screening tool for depression/anxiety and quality of life assessment: a systematic review of current research. Fam. Pr. 2019;36(3): 262-8.

37. Xi Y, Yu H, Yao Y, Peng K, Wang Y, Chen R. Post-traumatic stress disorder and the role of resilience, social support, anxiety and depression after the Jiuzhaigou earthquake: a structural equation model. Asian J Psychiatr. 2020; 49:101958. https://doi.org/10.1016/j.ajp.2020.101958.

38. Kay SA. Emotion regulation and resilience: overlooked connections. Ind Organ Psychol. 2016;9(2):411-5. https://doi.org/10.1017/iop.2016.31.

39. Tugade MM, Fredrickson BL. Resilient individuals use positive emotions to bounce back from negative emotional experiences. J Pers Soc Psychol. 2004;86(2):320-33. https://doi.org/10.1037/0022-3514.86.2.320.

40. Riolli L, Savicki V, Cepani A. Resilience in the face of catastrophe: optimism, personality, and coping in the Kosovo crisis. J Appl Soc Psychol. 2002:32(8): 1604-27. https://doi.org/10.1111/j.1559-1816.2002.tb02765.x.

41. Yu X, Zhang J. Factor analysis and psychometric evaluation of the ConnorDavidson resilience scale (CD-RISC) with Chinese people. Soc Behav Personal. 2007;35(1):19-30

42. Ni C, Chow MC, Jiang X, Li S, Pang SMC. Factors associated with resilience of adult survivors five years after the 2008 Sichuan earthquake in China. PloS one. 2015:10(3):e0121033.

43. Weiss EL, Longhurst JG, Mazure CM. Childhood sexual abuse as a risk factor for depression in women: psychosocial and neurobiological correlates. Am J Psychiat. 1999;156(6):816-28. 
44. Kritzas N, Grobler AA. The relationship between perceived parenting styles and resilience during adolescence. J Child Adolesc Ment. 2005;17(1):1-12. https://doi.org/10.2989/17280580509486586.

45. Zhong X, Wu D, Nie X, Xia J, Li M, Lei F, Lim HA, Kua E-H, Mahendran R. Parenting style, resilience, and mental health of community-dwelling elderly adults in China. BMC Geriatr. 2016;16(1):135.

46. van der Bruggen C, Stams G, Bögels S. Research review: the relation between child and parent anxiety and parental control: a meta-analytic review. J Child Psychol Psyc. 2008;49(12):1257-69. https://doi.org/10.1111/ j.1469-7610.2008.01898.x.

47. Nishikawa S, Sundbom E, Hägglöf B. Influence of perceived parental rearing on adolescent self-concept and internalizing and externalizing problems in Japan. J. Child Fam. Stud. 2010;19(1):57-66.

48. Reitman D, Asseff J. Parenting practices and their relation to anxiety in young adulthood. J Anxiety Disord. 2010;24(6):565-72. https://doi.org/10.101 6/j.janxdis.2010.03.016.

49. Neil AL, Christensen H. Australian school-based prevention and early intervention programs for anxiety and depression: a systematic review. Med. J. Med J Aust. 2007;186(6):305-8.

\section{Publisher's Note}

Springer Nature remains neutral with regard to jurisdictional claims in published maps and institutional affiliations.

Ready to submit your research? Choose BMC and benefit from:

- fast, convenient online submission

- thorough peer review by experienced researchers in your field

- rapid publication on acceptance

- support for research data, including large and complex data types

- gold Open Access which fosters wider collaboration and increased citations

- maximum visibility for your research: over $100 \mathrm{M}$ website views per year

At BMC, research is always in progress.

Learn more biomedcentral.com/submissions 